\title{
The Culture of Pediococcus pentosaceus T1 Inhibits Listeria Proliferation in Salmon Fillets and Controls Maturation of Kimchi
}

\author{
Seongho Jang ${ }^{1}$, Dongyun Lee ${ }^{1}$, Il Sang Jang ${ }^{1}$, Hyeon-Son Choi ${ }^{2 *}$ and Hyung Joo Suh ${ }^{3 *}$ \\ ${ }^{1}$ Our Home Co. Ltd, 462-819 Seongnam, South Korea \\ ${ }^{2}$ Department of Food Science and Technology, Seoul Women's University, 139-774 Seoul, South Korea \\ ${ }^{3}$ Department of Food and Nutrition, Korea University, 136-713 Seoul, South Korea
}

Received: June 6, 2014

Accepted: October 31, 2014

\begin{abstract}
Summary
The objective of this study is to evaluate the antilisterial effect of Pediococcus pentosaceus T1, which was isolated from kimchi, and to assess its potential for extending the shelf life of salmon and kimchi. Pediococcus pentosaceus T1 culture effectively inhibited proliferation of Listeria monocytogenes in a dose-dependent manner in a salmon-based medium. Antilisterial effect of the culture was stronger than that of nisin, an antibacterial peptide, as evidenced by lower minimum inhibitory concentration value $(20 \mathrm{mg} / \mathrm{mL})$ compared to ni$\sin$ (over $20 \mathrm{mg} / \mathrm{mL}$ ). P. pentosaceus T1 culture also effectively inhibited the growth of Listeria in salmon fillet. In particular, the culture $(6 \mathrm{~g}$ per $100 \mathrm{~mL})$ showed a stronger inhibitory effect than sodium hypochlorite $(0.2 \mathrm{mg} / \mathrm{mL})$, a disinfectant used in food processing. In kimchi fermentation, the treatment with $P$. pentosaceus $\mathrm{T} 1$ culture suppressed changes of acidity and $\mathrm{pH}$ during maturation. The inhibitory effect of the culture on kimchi lactic acid bacteria, which include Leuconostoc mesenteroides and Lactobacillus sakei, led to a drastic decrease in maturation rates of kimchi. Moreover, sensory test on kimchi treated with P. pentosaceus T1 showed that the culture improved overall acceptability of kimchi, which can be observed in higher scores of sourness, texture, off-flavour and mouthfeel compared with untreated kimchi. The results of this study suggest that kimchi-derived P. pentosaceus T1 could be a potential antilisterial agent in fish products as well as a starter to control overmaturation of kimchi.
\end{abstract}

Key words: Pediococcus pentosaceus T1, kimchi, salmon fillets, antilisterial activity, antibacterial activity

\section{Introduction}

Lactic acid bacteria (LAB), highly beneficial microorganisms for humans, have been used for a long time in fermented products such as fermented milk, sausages and kimchi $(1,2)$. They are usually Gram-positive, catalase-negative, and non-spore-forming bacteria (1). They are classified into various genera including Lactobacillus, Leuconostoc, Streptococcus, Lactococcus and Pediococcus. The properties of LAB are numerous: the enhancement of food preservation and flavour by their metabolites, antimicrobial effect against harmful bacteria, and supply of nutrients. The biological effects of LAB on human health have been studied in various research areas (1). These effects include activation of immunity, anticancer activity, reduction of cholesterol level and liver protection (3-6). A recent study has shown the suppressive effect on allergy such as atopic dermatitis by lactic acid bacteria via cell line and animal studies (7). 
Kimchi is a traditional fermented vegetable dish in Korea, which has centuries long historical records of consumption (1). Its fermentation is a spontaneous process that is initiated by various microorganisms originally present in the raw materials for kimchi production (1). The microorganisms in kimchi include approx. 200 species of bacteria and several yeasts, which are involved in a series of fermentation stages. Various LAB species, among which Pediococcus spp., have been isolated from kimchi, and their different technological characteristics have been studied $(8,9)$. This strain is known to be used in the American-style fermented meat and vegetables as a main starter culture (10). It produces bacteriocin called pediocin, which usually possesses antilisterial activity. Recent studies have shown that pediocins or pediococcus cultures inhibit Listeria monocytogenes in fermented sausages or sala$\mathrm{mi}(11,12)$. L. monocytogenes, a major human pathogen, is a bacterium causing listeriosis, a serious bacterial disease (13). Elderly people, newborns, and pregnant women, who have weakened immune systems, are susceptible to this disease, which is accompanied by sepsis and meningitis with high mortality rate (14).

Safe preservation of food is one of the critical issues in food industry. Traditionally, control of temperature such as by heating or refrigeration has usually been used for food preservation. However, these treatments can have high cost and cause the change of the components of food products, which results in the loss of food nutrients and changes in flavour, recognized as unnatural by consumers. In addition, the occurrence of psychrophilic pathogens does not guarantee safety in food preservation based on low temperature. Synthetic preservatives are used as an alternative way for food preservation, but they can be unfavourable for human health (15). Therefore, in recent years, biopreservation using biomaterials has received attention as a way of food preservation, with a trend demanding fresh and natural products. $\mathrm{LAB}$ are one of the good sources for biopreservation.

One of the beneficial properties of LAB is the production of antimicrobial substances like bacteriocin (13), which are used for biopreservation. Bacteriocin such as nisin is admitted as a GRAS (Generally Recognized As Safe) (16), and many European countries use nisin as a food preservative in commercial food products including canned food, mayonese and cheese (17).

In our previous study, we isolated a strain from kimchi and identified it by ribosomal DNA sequence analysis as the antilisterial strain Pediococcus pentosaceus T1 (18). In this study, we examine the antilisterial effect of $P$. pentosaceus $\mathrm{T} 1$ culture in fish products like salmon fillet, and its effect on maturation and quality of kimchi.

\section{Materials and Methods}

\section{Isolation and identification of the $L A B$ that produce antibacterial agents}

Commercial kimchi was obtained from a store (Seoul, Korea), the samples were unwrapped, transferred to stomacher filter bags and mixed with sterile phosphate buffer $(0.625 \mathrm{mM}, \mathrm{pH}=7.2)$. The samples were homogenized with a BagMixer ${ }^{\circledR} 400$ VW (Interscience, Saint-
-Nom-la-Bretèche, France) at $300 \times g$ for $5 \mathrm{~min}$, then serially diluted and plated onto de Man, Rogosa and Sharpe (MRS) agar (BD Difco, Detroit, MI, USA), followed by incubation under anaerobic conditions using the GasPak ${ }^{\mathrm{TM}}$ system (GENbox anaerobic indicator, bioMérieux S.A, Marcy l'Etoile, France) at $37-42{ }^{\circ} \mathrm{C}$ for $48 \mathrm{~h}$. Colonies were Gram stained and tested for catalase. Gram-positive and catalase-negative bacilli or coccobacilli were selected (18). For identification of LAB that produce antibacterial agents, rDNA PCR analysis was performed. Genomic DNA was extracted using DNeasy tissue kit (Qiagen, Hiden, Germany), and PCR reaction for the amplification of $16 \mathrm{~S}$ rDNA was performed using 20 pmol of universal bacterial primers: 27F (50-AGAGTTTGATCCTGGCTCA-30) and 1492R (50-GGTTACCTTGTTACGACTT-30) (19), and template DNA, 100 mM dNTP, 1 U of Taq DNA polymerase (Roche, Mannheim, Germany). After thermocycling amplification (18), agarose gel electrophoresis was performed to confirm PCR products. 16S rDNA from the gel was collected, purified using Solgent gel and PCR purification system (Solgent, Daejeon, South Korea), and then compared with $16 S$ rDNA sequences of other strains using the BLAST programs in the National Center for Biotechnology Information database (Rockville Pike, Bethesda, MD, USA) and the EzTaxon server v. 2.1 (20) by Solgent. Phylogenetic analyses of the $16 \mathrm{~S}$ rRNA gene sequences were conducted using Molecular Evolutionary Genetics Analysis (MEGA) software, v. 5 (21).

\section{Antilisterial activity of $L A B$ from kimchi}

Antilisterial activity of the isolated LAB strains was tested using an agar well diffusion method, as described by de Carvalho et al. (22). One hundred and twenty five LAB were cultured overnight by inoculating $10^{5} \mathrm{CFU} / \mathrm{mL}$ in tryptic soy broth (TSB; BD Difco). The agar well diffusion assay was performed by spreading Listeria monocytogenes cultures on tryptic soy agar (TSA) plates (BD Difco). Wells of $6.5 \mathrm{~mm}$ in diameter were punched in these plates, filled with $50 \mathrm{~mL}$ of cell-free culture supernatants of LAB and incubated at $35{ }^{\circ} \mathrm{C}$ for $24 \mathrm{~h}$. Antilisterial activities were measured by examining the diameters of the inhibition zones around the wells. The inhibitory activities corresponding to the diameters of the inhibition zones were expressed in $\mathrm{mm}$.

\section{Culture conditions and preparation of crude superna- tant}

The composition of the culture medium was as follows (in \%): sucrose 1.5 and fructose 1.5 (carbon source), soya peptone and yeast extract 1.5 (nitrogen source), $\mathrm{K}_{2} \mathrm{H}$ $\mathrm{PO}_{4}$ 0.1, sodium acetate 0.1 , tryptophan 0.05 , cysteine $0.05, \mathrm{MgSO}_{4}$ 0.01, and $\mathrm{MnSO}_{4}$ 0.005. A 5-litre laboratory scale fermentor (FMT ST-D, Fermentech, Cheongju, South Korea) was used for the growth of LAB under anaerobic conditions at $35{ }^{\circ} \mathrm{C}$, with stirring at $100 \times g$ for $20 \mathrm{~h}$. The fermented culture was centrifuged at $8000 \times g$ for $30 \mathrm{~min}$, and the supernatant was autoclaved at $100{ }^{\circ} \mathrm{C}$ for $15 \mathrm{~min}$ to inactivate proteases. Organic acids in the culture were removed by ultrafiltration (molecular mass cut-off $<3 \mathrm{kDa}$ ). The filter sludge was lyophilized for the study. 


\section{Listeria cultivation, salmon medium preparation, and antilisterial determination}

Listeria monocytogenes KCCM 40307 was inoculated on TSA (BD Difco) corresponding to the cell number of $10^{8}$ cells per mL. This Listeria solution was diluted to $10^{5}$ cells per mL in $200 \mathrm{~mL}$ of TSB (BD Difco) containing Pediococcus pentosaceus $\mathrm{T} 1$ culture at mass per volume ratios of $1,2,3$ and $4 \%$, and incubated at $35^{\circ} \mathrm{C}$. The Listeria culture was harvested at $6,9,12,15$ and $18 \mathrm{~h}$ to count viable cell numbers on Listeria selective medium, an Oxford Medium Base (BD Difco) containing antimicrobial supplement (BD Difco). For antimicrobial activity of nisin (Sigma-Aldrich, St. Louis, MO, USA) and P. pentosaceus T1 culture, raw salmon (10 g) was ground under aseptic conditions, and added to TSB and phosphate buffer $(0.625 \mathrm{mM}$, $\mathrm{pH}=7.2)(10 \mathrm{~mL})$ to make a salmon-based medium. A volume of $100 \mu \mathrm{L}$ of Listeria culture was added to the salmon-based medium followed by the addition of nisin and $P$. pentosaceus T1 culture with serial dilutions (20, 10, 5, 2.5, 1.25 and $0.625 \mathrm{mg} / \mathrm{mL}$ ). The culture was incubated at 35 ${ }^{\circ} \mathrm{C}$ for $24 \mathrm{~h}$, and spread onto Listeria selective medium. Minimal inhibitory concentration (MIC) was set where viable Listeria was not observed on the plate.

\section{Antilisterial activity in raw salmon fillet}

Frozen salmon was thawed, and sliced into fillets (200 g). Three fillets were used to examine the antilisterial activity of each P. pentosaceus T1 culture or sodium hypochlorite (ACL-60G, Namkang, Bucheon, South Korea) treatment. The fillets were inoculated with Listeria culture $\left(10^{6} \mathrm{CFU} / \mathrm{mL}\right)$, and then rested for $2 \mathrm{~h}$ at room temperature. Afterwards, they were dipped in sodium hypochlorite $(0.2 \mathrm{mg} / \mathrm{mL})$ or the $P$. pentosaceus $\mathrm{T} 1$ culture solution $(6 \mathrm{~g}$ per $100 \mathrm{~mL})$ for $10 \mathrm{~min}$, or sprayed with sodium hypochlorite or the culture solution. The fillets were incubated in the refrigerator at $4{ }^{\circ} \mathrm{C}$ for $24 \mathrm{~h}$. Listeria cells were taken from the fillets by grinding them and diluting with phosphate buffer $(0.625 \mathrm{mM}, \mathrm{pH}=7.2)$, followed by spreading on the Listeria selective medium for counting the Listeria cells.

\section{Antimicrobial activity on $L A B$ from kimchi}

Antimicrobial activity of the isolated P. pentosaceus T1 on LAB from kimchi was tested using an agar well diffusion method, as described by Jang et al. (18). Indicator strains, including $16 \mathrm{LAB}$ strains, were cultured overnight by inoculating $10^{5} \mathrm{CFU} / \mathrm{mL}$ in MRS medium (BD Difco). Sixteen strains of LAB were obtained from Korean Collection of Type Cultures (KCTC, Daejeon, Korea). The agar well diffusion assay was performed by spreading the LAB cultures on MRS agar plates (BD Difco). Wells of 6.5 $\mathrm{mm}$ in diameter were punched in these plates, filled with $50 \mu \mathrm{L}$ of cell-free supernatants of $P$. pentosaceus T1, from which organic acid was removed, and incubated at $35^{\circ} \mathrm{C}$ for $24 \mathrm{~h}$. Antimicrobial activity was examined by measuring the diameters of inhibition zones around the wells. When the diameters of the clear zones were wider than $6.5 \mathrm{~mm}$, the LAB were considered to be inhibited by $P$. pentosaceus $\mathrm{T} 1$. The inhibitory activity corresponding to the diameters of the inhibition zones was expressed in $\mathrm{mm}$.

\section{Preparation of kimchi}

Kimchi was prepared in batches up to $500 \mathrm{~kg}$ at a kimchi factory (Our Home Co. Ltd, Seongnam, South Korea) using their production line. Chinese cabbage (Brassica campestris L. ssp. pekinensis Rupr.) was soaked in a solution of refined salt ( $80 \mathrm{~g} / \mathrm{L}$, Hanju Co, Ulsan, Korea) for 2 to $4 \mathrm{~h}$, and washed 3 times with tap water. The washed Chinese cabbages were left to drain any excess water in a wicker container at 5 to $10{ }^{\circ} \mathrm{C}$ for 2 to $4 \mathrm{~h}$. The salted Chinese cabbages were then mixed with the other kimchi ingredients including red pepper powder, radish, garlic, ginger, onion, sugar and fermented fish sauce. The final salt mass fraction of the kimchi was adjusted to 1.9 to 2.1 $\%$ using refined salt. The filtered culture of Pediococcus pentosacesus T1 was inoculated into kimchi preparation (1 $\%, 10 \mathrm{~g} / \mathrm{kg}$ ). As a control, the same kimchi recipe was used without the filtered culture of Pediococcus pentosacesus T1. The prepared kimchi was vacuum packed into 500-gram retort packages with polyethylene resin and incubated at $10{ }^{\circ} \mathrm{C}$ in a refrigerator (Daehan Science, Seoul, Korea) for 105 days.

\section{Chemical analysis of kimchi}

Ripened kimchi (500 g) was macerated using a hand blender (Hanil, Seoul, South Korea) for $2 \mathrm{~min}$. The kimchi juice was centrifuged at $5000 \times g$ for $5 \mathrm{~min}$, and the $\mathrm{pH}$ of the supernatant was tested with a $\mathrm{pH}$ meter (Mettler Toledo, Viroflay, France). The supernatant was then titrated with $0.1 \mathrm{M} \mathrm{NaOH}$ to $\mathrm{pH}=8.3$ to determine the total titratable acidity (TTA), which was expressed as:

$$
\mathrm{TTA}=V \cdot f \cdot k \cdot 100
$$

where $V$ is the volume of $0.1 \mathrm{M} \mathrm{NaOH}(\mathrm{mL}), f$ is the factor of $0.1 \mathrm{M} \mathrm{NaOH}$ solution, and $k$ is the constant of organic acid equivalent to $1 \mathrm{~mL}$ of $0.1 \mathrm{M} \mathrm{NaOH}$ solution (in the case of lactic acid $k=0.009$ ).

\section{Microbial analysis of kimchi}

For the microbial analysis, kimchi samples were randomly selected and blended for $2 \mathrm{~min}$. The juice samples were filtered with a sterile sieve (pore size: $0.15 \mathrm{~mm}$, Chung Gye Sang Gong SA, Seoul, South Korea) and the aliquots of each filtrate were serially diluted with $0.1 \%$ peptone water and spread onto plate count agar (PCA; Merck, Darmstadt, Germany) for total microbial counts. The plates were counted after 2 to 3 days of incubation at $37^{\circ} \mathrm{C}$. Among the serially diluted plates, those with 30 to $300 \mathrm{CFU} / \mathrm{mL}$ were used for enumeration of the total microbial population in the kimchi samples.

\section{Sensory analysis}

Thirty-five panellists comprising 20- to 35-year-old housewives evaluated the acceptability of kimchi. Colour, sourness, sweetness, fizzy mouthfeel, mouldy flavour (off-flavour) and overall acceptability were scored using a 9-point hedonic scale: $1=$ very bad, $5=$ moderate and $9=$ very good.

\section{Statistical analysis}

Statistical analysis was performed using the SPSS-PC v. 11.0 software (SPSS, Chicago, IL, USA). Data were sub- 
jected to ANOVA, and the mean values were separated using Duncan's multiple-range test, with significance at $p<0.05$. For the significance of the differences between the given samples and control group, Student's $t$-test was used $(\mathrm{p}<0.05)$.

\section{Results and Discussion}

\section{Isolation of antibacterial $L A B$ from kimchi}

One hundred and twenty five strains of $\mathrm{LAB}$ were isolated based on Gram-positive staining and catalase reaction. Antilisterial activity of the LAB was examined using well diffusion assay. Twenty LAB strains (SN2, SN3,

Table 1. Antilisterial activity of LAB from kimchi

\begin{tabular}{|c|c|c|c|c|c|c|c|}
\hline ڤే & 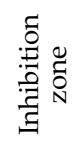 & 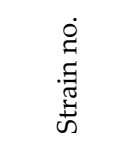 & 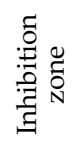 & 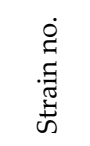 & 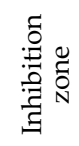 & 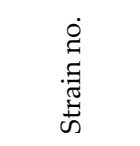 & 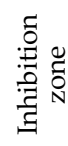 \\
\hline SN01 & - & SN32 & - & SN63 & - & SN94 & - \\
\hline SN02 & + & SN33 & - & SN64 & - & SN95 & - \\
\hline SN03 & ++ & SN34 & - & SN65 & + & SN96 & - \\
\hline SN04 & - & SN35 & - & SN66 & + & SN97 & - \\
\hline SN05 & + & SN36 & - & SN67 & - & SN98 & - \\
\hline SN06 & - & SN37 & - & SN68 & + & SN99 & - \\
\hline SN07 & - & SN38 & - & SN69 & - & SN100 & - \\
\hline SN08 & + & SN39 & - & SN70 & - & SN101 & + \\
\hline SN09 & - & SN40 & - & SN71 & - & SN102 & - \\
\hline SN10 & ++ & SN41 & - & SN72 & - & SN103 & - \\
\hline SN11 & - & SN42 & - & SN73 & - & SN104 & - \\
\hline SN12 & + & SN43 (T1) & +++ & SN74 & - & SN105 & - \\
\hline SN13 & - & SN44 & - & SN75 & - & SN106 & - \\
\hline SN14 & + & SN45 & - & SN76 & - & SN107 & - \\
\hline SN15 & - & SN46 & + & SN77 & - & SN108 & - \\
\hline SN16 & - & SN47 & ++ & SN78 & - & SN109 & - \\
\hline SN17 & - & SN48 & + & SN79 & - & SN110 & - \\
\hline SN18 & - & SN49 & - & SN80 & - & SN111 & - \\
\hline SN19 & + & SN50 & - & SN81 & - & SN112 & - \\
\hline SN20 & - & SN51 & - & SN82 & - & SN113 & - \\
\hline SN21 & - & SN52 & ++ & SN83 & - & SN114 & - \\
\hline SN22 & + & SN53 & - & SN84 & - & SN115 & - \\
\hline SN23 & - & SN54 & + & SN85 & - & SN116 & - \\
\hline SN24 & - & SN55 & - & SN86 & - & SN117 & - \\
\hline SN25 & - & SN56 & - & SN87 & - & SN118 & - \\
\hline SN26 & - & SN57 & - & SN88 & - & SN119 & - \\
\hline SN27 & - & SN58 & - & SN89 & - & SN120 & - \\
\hline SN28 & - & SN59 & ++ & SN90 & - & SN121 & - \\
\hline SN29 & - & SN60 & - & SN91 & - & SN122 & - \\
\hline SN30 & - & SN61 & - & SN92 & - & SN123 & - \\
\hline SN31 & - & SN62 & - & SN93 & - & SN124/125 & - \\
\hline
\end{tabular}

$-=$ no inhibition zone, $+=$ radius of inhibition zone $<3 \mathrm{~mm}$, $++=$ radius of inhibition zone 4 to $6 \mathrm{~mm},+++=$ radius of inhibition zone $>6 \mathrm{~mm}, \mathrm{~T} 1=$ Pediococcus pentosaceus $\mathrm{T} 1$
SN5, SN8, SN10, SN12, SN14, SN19, SN22, SN43, SN46, SN47, SN48, SN52, SN54, SN59, SN65, SN66, SN68 and SN101) were shown to have an inhibitory effect on $L$. monocytogenes. Among them, the strain SN43 demonstrated the strongest antilisterial activity by showing the inhibition zone of over $6.5 \mathrm{~mm}$ in agar well diffusion assay (Table 1). We had identified SN43 strain as Pediococcus pentosaceus T1 via rDNA PCR analysis in the previous study (18). Therefore, we used the culture of P. pentosaceus $\mathrm{T} 1$ for subsequent experiments.

\section{Effect of P. pentosaceus T1 culture on L. monocyto- genes proliferation}

The inhibitory effect of the $P$. pentosaceus T1 culture against Listeria at different doses was determined. Listeria monocytogenes growth greatly increased until $12 \mathrm{~h}$ in the control group, reaching $1.3 \cdot 10^{9} \mathrm{CFU} / \mathrm{mL}$, after which it gradually decreased to $5.8 \cdot 10^{7} \mathrm{CFU} / \mathrm{mL}$ (Fig. 1). In contrast, the treatment with the culture significantly inhibited cell proliferation of Listeria at all tested concentrations. After $6 \mathrm{~h}$, the number of Listeria monocytogenes cells in all samples treated with the culture was $10^{4}$ to $10^{5} \mathrm{CFU} / \mathrm{mL}$. The culture containing $1 \% P$. pentosaceus $\mathrm{T} 1$ showed a small increase of the number of Listeria monocytogenes cells after $6 \mathrm{~h}$ (Fig. 1). However, the number of Listeria monocytogenes cells at the other mass per volume ratios of the culture $(2,3$ and $4 \%)$ continually decreased after $6 \mathrm{~h}$. In particular, $4 \%$ of the culture caused a dramatic decrease after $18 \mathrm{~h}$, with less than $10^{2} \mathrm{CFU} / \mathrm{mL}$ of Listeria cells. Thus, the treatment with $P$. pentosaceus T1 culture showed an effective inhibitory effect on Listeria monocytogenes in a dose-dependent manner. Our results indicate that the substances produced by P. pentosaceus $\mathrm{T} 1$ have an ability to inhibit Listeria monocytogenes.

Previously, we had isolated P. pentosaceus T1 as an antilisterial LAB from kimchi (18). In general, Pediococcus spp. have been known to exhibit antilisterial activity like Lactobacillus spp. (23). Recent studies have reported antilisterial activity of Pediococcus spp. from various sources $(23,24)$. Pediococcus spp. were also known to inhibit other

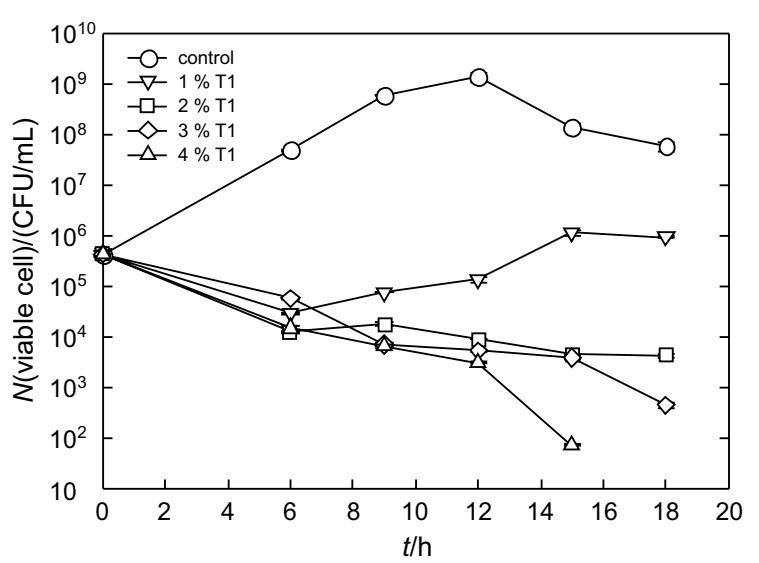

Fig. 1. Effect of P. pentosaceus T1 culture (T1) on Listeria monocytogenes proliferation. L. monocytogenes was grown in the presence or absence of various mass per volume ratios of the culture (powder) for $18 \mathrm{~h}$. Listeria cultures harvested at 6, 9, 12, 15 and $18 \mathrm{~h}$ were spread onto Listeria monocytogenes selective medium to count the viable cells. Data are expressed as mean values \pm standard deviation (S.D.) $(N=3)$ 
pathogens such as Escherichia coli and Staphylococcus aureus (25). A major antimicrobial substance from Pediococcus spp. has been found to be a bacteriocin called pediocin, which is classified into Class II (24). Its molecular size is less than $5 \mathrm{kDa}$ containing 36-48 residues (25). However, our series of analyses including chromatography showed that $P$. pentosaceus T1-derived antilisterial material was proteinous substance with a molecular size of $23 \mathrm{kDa}(18)$. In addition, liquid chromatography-mass spectrometry showed that $P$. pentosaceus T1-derived antimicrobial substance contained LysM domain (18), which is known to hydrolyze peptidoglycan, a cell wall component (26). Therefore, the active substance from our sample could be considered as a novel antilisterial substance, which is different from pediocin. $\mathrm{LAB}$ have been known to produce organic acids to inhibit other microbes, and these acids are possibly major antilisterial substances found in this work. However, we removed organic acids from the culture by ultrafiltration (cut off $<3 \mathrm{kDa}$ ) to exclude this potential from our investigation. Lactic and acetic acids, at concentrations of 19.9 and $2.6 \mathrm{~g} / \mathrm{L}$ respectively, before ultrafiltration were completely removed after ultrafiltration from the culture.

\section{Antilisterial effects of P. pentosaceus T1 culture and nisin in raw salmon medium}

We compared the antilisterial effect of our sample $(P$. pentosaceus T1 culture) with that of nisin, a known bacteriocin with antilisterial activity. For this experiment, the raw salmon medium was inoculated with Listeria monocytogenes culture. Our culture and nisin were tested on Listeria in salmon in various doses to get minimum inhibitory concentrations (MIC). The number of Listeria cells in raw salmon medium significantly decreased with both treatments in a dose-dependent manner. Based on our data, inhibitory effect of the culture on Listeria proliferation was shown to be stronger than that of nisin (Fig. 2), showing a more decreased number of Listeria cells at most of the treatment concentrations. MIC value of the culture was $20 \mathrm{mg} / \mathrm{mL}$, while that of nisin was over $20 \mathrm{mg} / \mathrm{mL}$. This result shows that $P$. pentosaceus $\mathrm{T} 1$ produces stronger antilisterial substances than nisin. Considering that our culture sample was not completely purified, it is believed

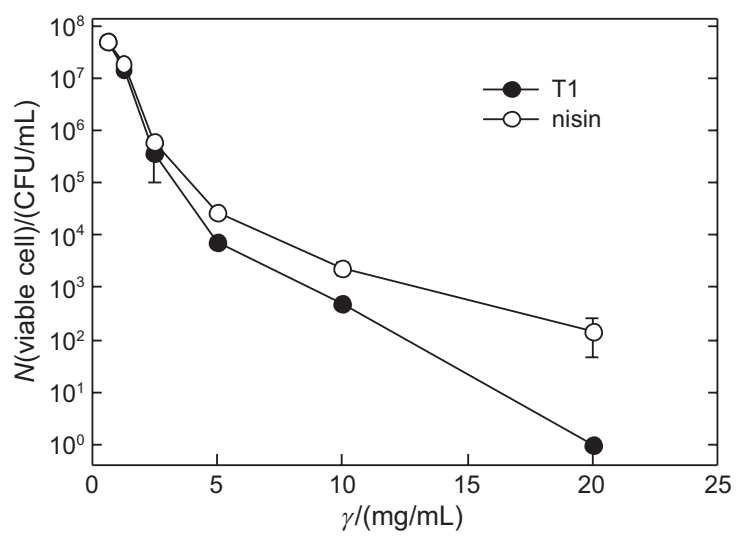

Fig. 2. Antilisterial effects of P. pentosaceus T1 culture (T1) and nisin, which were added to L. monocytogenes-inoculated salmon medium at serially diluted concentrations to test the antilisterial effects for $24 \mathrm{~h}$ at $35{ }^{\circ} \mathrm{C}$. Data are expressed as mean values \pm S.D. $(N=3)$ that real antilisterial activity of $P$. pentosaceus T1-derived active substance is underestimated. However, this result might be different under different conditions because optimal conditions for antimicrobial activity of nisin can be different from those of our samples. Generally, nisin is known to be more active in acidic $\mathrm{pH}$, which is related to its cell membrane permeation (27-29). In contrast, another study reported that nisin was rather less sensitive to foodborne pathogens such as Staphylococcus aureus and Listeria monocytogenes in the acidic $\mathrm{pH}(\mathrm{pH}=4.5-5)(30)$. Our test of antilisterial activity of nisin and P. pentosaceus T1 culture was performed under the optimal growth conditions for L. monoctogenes ( $\mathrm{pH}=7.2$ and $35^{\circ} \mathrm{C}$ ) to count viable Listeria cells in the selective medium. Since our previous study had shown that the culture had broader spectrum of $\mathrm{pH}$ and temperature for maximal antilisterial activity (31), it could be more favourable as an antilisterial agent in food products. However, the application of antimicrobial materials on food is more complex due to various factors such as salt concentration and temperature, which affect the antimicrobial activity (30). Therefore, further detailed analysis of antilisterial effects of both samples will be performed in the next study.

\section{Antilisterial effect of $P$. pentosaceus T1 culture on salmon fillets inoculated with Listeria monocytogenes}

Fish is highly susceptible to contamination with food pathogens like L. monocytogenes, causing a serious food-derived infection globally (32). We tested the antilisterial effect of our culture sample on a fish product contaminated with Listeria. Listeria-inoculated salmon fillets were dipped and sprayed with our samples and sodium hypochlorite. After incubation for $24 \mathrm{~h}$ at $4{ }^{\circ} \mathrm{C}$, significant decreases in the bacterial cell numbers were observed in sample-treated groups (Fig. 3). Treatment with sodium hypochlorite, a disinfectant normally used in fish product processing, also showed a significant reduction of Listeria cells. Interestingly, our culture caused a dramatic decrease in the number of Listeria cells after the treatment (Fig. 3). The culture showed a much stronger inhibitory effect on Listeria growth compared with sodium hypochlorite $(0.2$ $\mathrm{mg} / \mathrm{mL}$, ACL-60G), which served as a positive control. However, we cannot directly compare the inhibitory effects of $P$. pentosaceus T1 culture and ACL-60G disinfectant because the concentrations of the two samples were different in the treatments, where $0.2 \mathrm{mg} / \mathrm{mL}$ of ACL-60G is maximum allowed criterion in food processing. Nevertheless, P. pentosaceus T1 culture $(6 \mathrm{~g}$ per $100 \mathrm{~mL}$ ) clearly has an inhibitory effect on Listeria growth in salmon product. Therefore, P. pentosaceus T1 culture could be used as an inhibitor of Listeria contamination in fish products. This result is correlated with the data derived from the experiment performed in raw salmon medium (Fig. 2). Our data suggest an applicable potential of $P$. pentosaceus $\mathrm{T} 1$ in raw fish product processing in food industry.

\section{Effects of P. pentosaceus T1 culture on acidity and $p H$ changes in kimchi during fermentation}

To examine the effect of $P$. pentosaceus T1 culture on the maturation of kimchi, we determined the changes in the $\mathrm{pH}$ values and titratable acidity of kimchi preparations during fermentation at $10{ }^{\circ} \mathrm{C}$ for 105 days (Fig. 4). When the kimchi was prepared (0 day fermentation), the 
a)

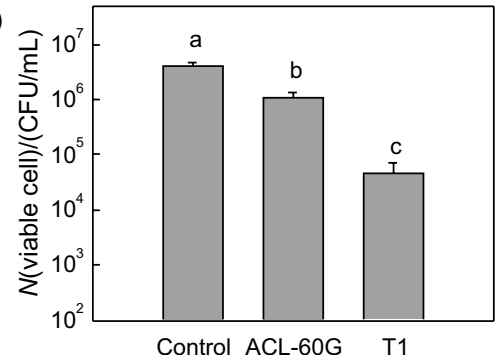

b)

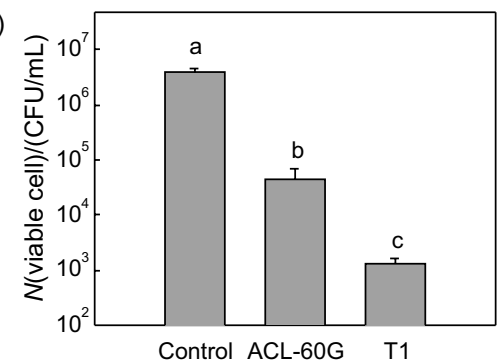

Fig. 3. Antilisterial effect of $P$. pentosaceus T1 culture (T1, 6 g per $100 \mathrm{~mL}$ ) on salmon fillets inoculated with Listeria monocytogenes. Salmon fillets were inoculated with Listeria and: a) dipped, or b) sprayed with disinfectant ACL-60G or P. pentosaceus T1 solution. Treated salmon fillets were incubated for $24 \mathrm{~h}$ at $4{ }^{\circ} \mathrm{C}$, swabbed with cotton and diluted with phosphate buffer. The dilutions were spread onto Listeria selective medium to count the cells. Data show mean values \pm S.D. $(N=3)$. Different letters indicate significant differences $(\mathrm{p}<0.05) . \gamma(\mathrm{ACL}-60 \mathrm{G})=0.2 \mathrm{mg} / \mathrm{L}$

total acidity was $0.40-0.42 \%$, and $\mathrm{pH}$ values were $5.4-5.6$. The acidity of the fermented kimchi without the culture treatment (control) increased faster than that of the culture-treated kimchi, reaching $1.21 \%(\mathrm{pH}=4.02)$ within 21 days (Fig. 4), after which it remained stable until the 105th day $(1.28 \%, \mathrm{pH}=3.89)$. The acidity of the kimchi treated with the culture increased very slowly during fermentation, and reached up to $0.66 \%$ at $\mathrm{pH}=4.66$ in 105 days (Fig. 4). Fast increase of acidity during fermentation in control kimchi resulted in rapid decrease of $\mathrm{pH}$ value, while the culture treatment deferred these changes. According to our data, normal kimchi acidity reached $1 \%$ at around day 15 , but the culture-treated kimchi never reached that acidity during entire fermentation (Fig. 4a).

Sensory quality of kimchi depends on the duration of maturation, which means that its optimal quality is maintained only for a certain period of time. Today, kimchi is commercially produced and sold via distribution networks. The supply of fresh and tasty kimchi is one of the important challenges for producers. During fermentation of kimchi, prolonged maturation allows proliferation of other putrefying or spoilage bacteria as well as deterioration of quality, which increases the acidity above $1 \%$ (33). Thus, acidity is used as a direct indicator of prolonged maturation (33). Usually, the acidity of kimchi in early fermentation stage is known to be in the range of $0.4-0.6 \%$, after which it increases over $1 \%$ at around day 30 (34). The acidity of kimchi in our work reached $1 \%$ in 15 days, earlier than in the study by Shin et al. (34), suggesting faster maturation of the kimchi in our study. This result could be due to the differences in compositions of ingredients, which can affect LAB proliferation. Several studies have shown that optimal acidity is $0.5-0.75 \%$, and kimchi
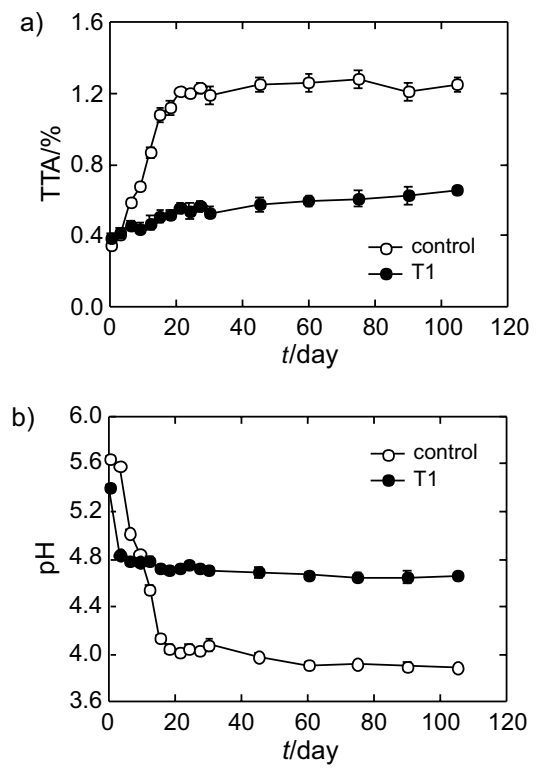

Fig. 4. Effect of P. pentosaceus T1 culture (T1) on the acidity and $\mathrm{pH}$ changes in kimchi during fermentation. P. pentosaceus T1 (1 $\%$ ) was added to kimchi preparation, and the changes of: a) total titratable acidity (TTA), and b) $\mathrm{pH}$ were measured during fermentation. Data are expressed as mean values \pm S.D. $(N=3)$

with an acidity level over $1 \%$ is recognized as unacceptable for consumption $(34,35)$. Our results show that the treatment with the culture suppresses the increase of kimchi acidity during fermentation, maintaining it at $0.6 \%$. Normally fermented kimchi has an optimal acidity for maturity only for a short period of time (within 20 days), while culture-treated kimchi maintains optimal acidity for a longer time (105 days) (Fig. 4). Our data indicate that culture treatment could play an important role in controlling the acidity of kimchi with optimal maturity, which is desirable for distribution and storage of the product, and meets the commercial demands. Our findings suggest that the shelf life of kimchi could be properly extended using the P. pentosaceus T1 as a starter culture under optimal maturation conditions.

\section{Effect of P. pentosaceus T1 culture on total viable cell number in kimchi during fermentation}

Total viable cell number in two kimchi sample groups (control and culture-treated group) was determined during fermentation (Fig. 5). The initial total cell number was around 1.0-1.6·10 $\mathrm{CFU} / \mathrm{mL}$ in control and culture-treated kimchi. Similar numbers of cells in the two samples show a clear difference after 3 days of fermentation; cell number of control kimchi significantly increased to $2.1 \cdot 10^{7}$ $\mathrm{CFU} / \mathrm{mL}$, while the cell number of culture-treated kimchi decreased to $5.4 \cdot 10^{5} \mathrm{CFU} / \mathrm{mL}$. The increase of the cell number in control kimchi is correlated with the increase of acidity during early fermentation period. In control kimchi, cells continued to increase up to $2.7 \cdot 10^{8} \mathrm{CFU} / \mathrm{mL}$ and gradually decreased to $10^{7} \mathrm{CFU} / \mathrm{mL}$ in 105 days, but the culture-treated kimchi had a stable cell number in the range of 2 to $5 \cdot 10^{5} \mathrm{CFU} / \mathrm{mL}$ during the investigated fermentation period (Fig. 5). This result shows that the culture treatment inhibited cell proliferation during fermentation. The suppression of cell number occurred at an 


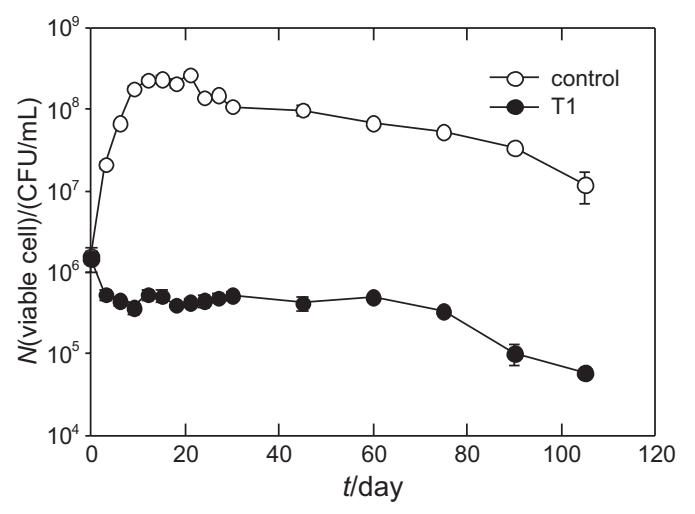

Fig. 5. Effect of P. pentosaceus T1 culture (T1, $6 \mathrm{~g}$ per $100 \mathrm{~mL})$ on total viable cell number in kimchi during fermentation. Kimchi samples were blended to prepare the juice. The juice samples were filtered, diluted, and spread onto plate count agar. The plate agar was counted after 2 to 3 days of incubation at $25^{\circ} \mathrm{C}$. Data are expressed as mean values \pm S.D. $(N=3)$

early stage of fermentation of samples treated with P. pentosaceus T1 culture, indicating that the culture could inhibit the growth of other $L A B$, which is responsible for overmaturation of kimchi, by producing antimicrobial substances including LysM domain. According to our results, P. pentosaceus T1 culture treatment could control the number of total cells, which can affect kimchi maturity or fermentation quality.

\section{Growth inhibition of indicator LAB by P. pentosaceus T1 culture}

The above data show that $P$. pentosaceus T1 culture suppressed the total cell viability in kimchi during fermentation. We then determined which LAB were inhibited by $P$. pentosaceus T1. Sixteen strains of LAB including Leuconostoc spp., Lactobacillus spp. and Weisella spp. were tested against $P$. pentosaceus T1. Well diffusion assay showed that the wells treated with $P$. pentosaceus $\mathrm{T} 1$ had significant inhibition zones, over $12 \mathrm{~mm}$, only against Leuoconostoc mesenteroides and Lactobacillus sakei (Fig. 6), suggesting that $P$. pentosaceus $\mathrm{T} 1$ has a strong antimicrobial activity on these two bacteria (Table 2). P. pentosaceus T1 also inhibited the other tested strains, although the inhibitory effects on them weakened compared to those on Leu. mesenteroides and L. sakei (Table 2). Leu. mesenteroides and

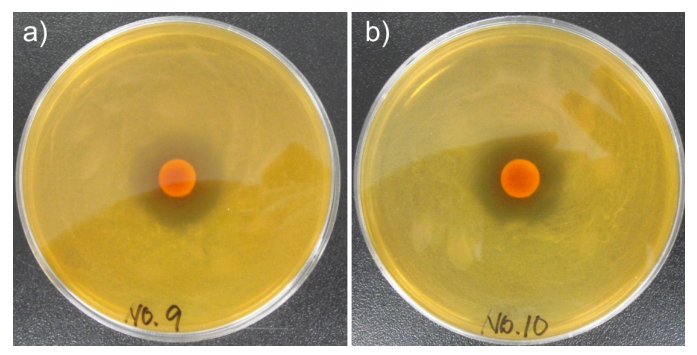

Fig. 6. Growth inhibition of: a) Leu. mesenteroides, and b) L. sakei by $P$. pentosaceus T1. Sixteen LAB were cultured overnight by inoculating $10^{5} \mathrm{CFU} / \mathrm{mL}$ in MRS broth. LAB cultures $(100 \mu \mathrm{L})$ were spread on MRS agar plates. Well diffusion assay was performed with $50 \mu \mathrm{L}$ of cell-free supernatants of P. pentosaceus T1. Data are representative of three independent experiments
Table 2. Antimicrobial activity of $P$. pentosaceus T1 against 16 indicator LAB strains

\begin{tabular}{|c|c|}
\hline Indicator strain & Antimicrobial activity \\
\hline Lactobacillus sakei KCTC 3603 & +++ \\
\hline Lactobacillus plantarum КСТС 3108 & ++ \\
\hline Lactobacillus paraplantarum KCTC 5045 & ++ \\
\hline Lactobacillus pentosus DSM 20314 & ++ \\
\hline Lactobacillus curvatus КСТС 3767 & ++ \\
\hline Leuconostoc citreum KCTC 3526 & ++ \\
\hline Leuconostoc carnosum КСТС 3525 & ++ \\
\hline Leuconostoc gasicomitatum KCTC 3753 & ++ \\
\hline Leuconostoc gelidum KCTC 3527 & ++ \\
\hline Leuconostoc kimchii KCTC 2386 & ++ \\
\hline Leuconostoc lactis КСТС 3528 & ++ \\
\hline Leuconostoc mesenteroides KCTC 3505 & +++ \\
\hline Leuconostoc inhae КСТС 3774 & + \\
\hline Weisella cibaria КСТС 3746 & + \\
\hline Weisella confusa KCTC 3499 & + \\
\hline Weisella koreensis КСТС 3621 & + \\
\hline
\end{tabular}

$+=$ radius of inhibition zone $<8 \mathrm{~mm},++=$ radius of inhibition zone 8 to $10 \mathrm{~mm},+++=$ radius of inhibition zone $>12 \mathrm{~mm}$

L. sakei are the major LAB in kimchi, which are responsible for its maturation during fermentation (1). Leu. mesenteroides is known to be a predominant strain in the early or middle stages of kimchi fermentation, and L. sakei is one of the predominant strains in the late stage of fermentation $(36,37)$. Moreover, the prolonged predominance of L. sakei can result in an excessively acidic taste and soft texture of kimchi (38). Thus, our P. pentosaceus T1 is thought to control the change of microflora during fermentation of kimchi by inhibiting various LAB including Leu. mesenteroids and L. sakei. Our result indicated that the inhibition of LAB by P. pentosaceus T1 could prevent prolonged maturation, maintaining proper fermentation level which could be induced by other non-inhibited LAB. In addition, it would be interesting to analyze the changes of overall LAB microflora in the presence or absence of $P$. pentosaceus $\mathrm{T} 1$ during kimchi fermentation in the next study.

\section{Sensory evaluation of kimchi}

We showed that our P. pentosaceus T1 culture could positively affect the kimchi quality by controlling the acidity and bacterial cell number. However, if the treatment with $P$. pentosaceus T1 culture negatively affected kimchi sensory properties, its beneficial effect such as antilisterial activity would be less meaningful. Therefore, we performed sensory evaluation of kimchi samples treated with $P$. pentosaceus T1 and the control. Sensory characteristics of kimchi include a proper combination of sour, sweet and salty tastes along with freshness, fizzy mouthfeel, and crunchy texture. Sensory properties of kimchi are shown in Table 3. Kimchi treated with P. pentosaceus $\mathrm{T} 1$ received a higher score on most of the items in sensory evaluation including overall acceptability compared with the control. Specifically, sourness, off-flavour 
Table 3. Sensory evaluation of kimchi

\begin{tabular}{lcc}
\hline Property & Kimchi+T1 & Control \\
\hline Overall acceptability & $(6.2 \pm 1.2)^{*}$ & $4.0 \pm 1.5$ \\
Colour & $5.6 \pm 0.1$ & $5.0 \pm 0.8$ \\
Sourness & $(6.9 \pm 1.8)^{*}$ & $2.7 \pm 1.4$ \\
Sweetness & $(5.8 \pm 0.6)^{*}$ & $5.0 \pm 1.3$ \\
Fizzy mouthfeel & $(6.9 \pm 1.4)^{*}$ & $3.2 \pm 1.1$ \\
Mouldy flavour (off-flavour) & $(6.0 \pm 1.1)^{*}$ & $4.0 \pm 1.1$ \\
Texture & $(5.7 \pm 0.7)^{*}$ & $4.6 \pm 1.3$ \\
\hline
\end{tabular}

*Significant differences between the values of the same tested property $(\mathrm{p}<0.05$, independent samples $t$-test). Results are expressed as mean values of scores on a 9-point hedonic scale

and fizzy mouthfeel were greatly improved when P. pentosaceus T1 culture was added to the kimchi as a starter. Colour differences between the starter and nonstarter kimchi preparations were not significant, but the kimchi treated with $P$. pentosaceus $\mathrm{T} 1$ had a brighter appearance than the control. Interestingly, the culture-treated kimchi had a characteristic flavour. This result showed that $P$. pentosaceus T1 delayed maturation stage, maintaining optimal kimchi quality. Accordingly, our data indicate that the use of $P$. pentosaceus $\mathrm{T} 1$ as a starter in kimchi preparation could prolong optimal conditions of kimchi fermentation, maintaining optimal sensory properties during storage or distribution.

\section{Conclusion}

In this study, we compared the antilisterial effect of Pediococcus pentosaceus T1 isolated from kimchi using salmon with a commercial bacteriocin (nisin) and a disinfectant (sodium hypochlorite). P. pentosaceus T1 was evaluated as a competitive antilisterial agent that showed a stronger inhibitory effect than nisin and the disinfectant. Current study also showed beneficial effects of $P$. pentosaceus T1 used as a starter culture on kimchi quality. P. pentosaceus $\mathrm{T} 1$ effectively controlled maturation of kimchi by suppressing lactic acid bacteria such as Leu. mesenteroides and L. sakei, which are responsible for kimchi maturation. Moreover, P. pentosaceus T1 culture improved organoleptic quality of kimchi, as shown by sensory evaluation. We suggest that $P$. pentosaceus $\mathrm{T} 1$ be used as an antilisterial agent in fish products as well as a starter to control the fermentation of kimchi.

\section{References}

1. Kanmani P, Satish Kumar R, Yuvaraj N, Paari KA, Pattukumar V, Arul V. Probiotics and its functionally valuable products-a review. Crit Rev Food Sci Nutr. 2013;53:641-58. http://dx.doi.org/10.1080/10408398.2011.553752

2. Park KY, Jeong JK, Lee YE, Daily 3rd JW. Health benefits of kimchi (Korean fermented vegetables) as a probiotic food. J Med Food. 2014;17:6-20. http://dx.doi.org/ 10.1089/jmf.2013.3083

3. Kim JE, Kim JY, Lee KW, Lee HJ. Cancer chemopreventive effects of lactic acid bacteria. J Microbiol Biotechnol. 2007;17: 1227-35.
4. Kim Y, Whang JY, Whang KY, Oh S, Kim SH. Characterization of the cholesterol-reducing activity in a cell-free supernatant of Lactobacillus acidophilus ATCC 43121. Biosci Biotechnol Biochem. 2008;72:1483-90. http://dx.doi.org/10.1271/bbb.70802

5. Onilude A, Fagade O, Bello M, Fadahunsi I. Inhibition of aflatoxin-producing aspergilli by lactic acid bacteria isolates from indigenously fermented cereal gruels. Afr J Biotechnol. 2005;4:1404-8.

6. Ren C, Zhang Q, Wang G, Ai C, Hu M, Liu X, et al. Modulation of peanut-induced allergic immune responses by oral lactic acid bacteria-based vaccines in mice. Appl Microbiol Biotechnol. 2014;98:6353-64. http://dx.doi.org/10.1007/s00253-014-5678-7

7. Hayashi A, Kimura M, Nakamura Y, Yasui H. Anti-atopic dermatitis effects and the mechanism of lactic acid bacteria isolated from Mongolian fermented milk. J Dairy Res. 2009; 76:158-64. http://dx.doi.org/10.1017/S0022029908003725

8. Rattanachaikunsopon P, Phumkhachorn P. Lactic acid bacteria: their antimicrobial compounds and their uses in food production. Ann Biol Res. 2010;1:218-28.

9. Shin MS, Han SK, Ryu JS, Kim KS, Lee WK. Isolation and partial characterization of a bacteriocin produced by Pediococcus pentosaceus K23-2 isolated from kimchi. J Appl Microbiol. 2008;105:331-9. http://dx.doi.org/10.1111/j.1365-2672.2008.03770.x

10. Raccach M, Tilley HR. Thermal inactivation of the frozen thawed traditional meat starter culture, Pediococcus pentosaceus, in a meat model system. Meat Sci. 2006;72:751-6. http://dx.doi.org/10.1016/j.meatsci.2005.10.005

11. Albano H, Todorov SD, van Reenen CA, Hogg T, Dicks LM, Teixeira P. Characterization of two bacteriocins produced by Pediococcus acidilactici isolated from 'Alheira', a fermented sausage traditionally produced in Portugal. Int J Food Microbiol. 2007;116:239-47.

http://dx.doi.org/10.1016/j.ijfoodmicro.2007.01.011

12. Mattila K, Saris P, Tyopponen S. Survival of Listeria monocytogenes on sliced cooked sausage after treatment with pediocin AcH. Int J Food Microbiol. 2003;89:281-6.

13. Popovic I, Heron B, Covacin C. Listeria: an Australian perspective (2001-2010). Foodborne Pathog Dis. 2014;11:425-32. http://dx.doi.org/10.1089/fpd.2013.1697

14. Miranda-Bautista J, Padilla-Suarez C, Bouza E, Munoz P, Menchen L, Marin-Jimenez I. Listeria monocytogenes infection in inflammatory bowel disease patients: case series and review of the literature. Eur J Gastroen Hepat. 2014;26:1247-52. http://dx.doi.org/10.1097/ MEG.0000000000000188

15. Leistner L. Basic aspects of food preservation by hurdle technology. Int J Food Microbiol. 2000;55:181-6.

16. Snyder AB, Worobo RW. Chemical and genetic characterization of bacteriocins: antimicrobial peptides for food safety. J Sci Food Agric. 2014;94:28-44. http://dx.doi.org/10.1002/jsfa.6293

17. Bali V, Panesar PS, Bera MB, Kennedy JF. Bacteriocins: Recent trends and potential applications, Crit Rev Food Sci Nutr. 2014; in press. http://dx.doi.org/10.1080/10408398.2012.729231

18. Jang S, Lee J, Jung U, Choi HS, Suh HJ. Identification of an anti-listerial domain from Pediococcus pentosaceus T1 derived from kimchi, a traditional fermented vegetable. Food Control. 2014;43:42-8. http://dx.doi.org/10.1016/j.foodcont.2014.02.040

19. Shim S, Lee J. Evaluation of lactic acid bacterial community in kimchi using terminal-restriction fragment length polymorphism analysis. Kor J Microbiol Biotechnol. 2008;36:247-59. 
20. Chun J, Lee JH, Jung Y, Kim M, Kim S, Kim BK, et al. EzTaxon: a web-based tool for the identification of prokaryotes based on $16 \mathrm{~S}$ ribosomal RNA gene sequences. Int J Syst Evol Microbiol. 2007;57:2259-61. http://dx.doi.org/10.1099/ijs.0.64915-0

21. Tamura K, Peterson D, Peterson N, Stecher G, Nei M, Kumar S. MEGA5: molecular evolutionary genetics analysis using maximum likelihood, evolutionary distance, and maximum parsimony methods. Mol Biol Evol. 2011;28:2731-9. http://dx.doi.org/10.1093/molbev/msr121

22. de Carvalho AA, de Paula RA, Mantovani HC, de Moraes CA. Inhibition of Listeria monocytogenes by a lactic acid bacterium isolated from Italian salami. Food Microbiol. 2006;23: 213-9.

http://dx.doi.org/10.1016/j.fm.2005.05.009

23. Eijsink VG, Axelsson L, Diep DB, Havarstein LS, Holo H, Nes IF. Production of class II bacteriocins by lactic acid bacteria; an example of biological warfare and communication. Anton Leeuw. 2002;81:639-54.

24. Beyatli Y, Gündüz U. Isolation and characterization of pediocin producing Pediococcus pentosaceus Pep1 from vacuumpacked sausages. Turk J Biol. 2001;25:133-43.

25. Kingcha Y, Tosukhowong A, Zendo T, Roytrakul S, Luxananil P, Chareonpornsook K, et al. Anti-listeria activity of Pediococcus pentosaceus BCC 3772 and application as starter culture for Nham, a traditional fermented pork sausage. Food Control. 2012;25:190-6. http://dx.doi.org/doi:10.1016/j.foodcont.2011.10.005

26. Buist G, Steen A, Kok J, Kuipers OP. LysM, a widely distributed protein motif for binding to (peptido) glycans. Mol Microbiol. 2008;68:838-47. http://dx.doi.org/10.1111/j.1365-2958.2008.06211.x

27. Adhikari MD, Das G, Ramesh A. Retention of nisin activity at elevated $\mathrm{pH}$ in an organic acid complex and gold nanoparticle composite. Chem Commun. 2012;48:8928-30. http://dx.doi.org/10.1039/c2cc34653b

28. Delves-Broughton J. Nisin as a food preservative. Food Australia. 2005;57:525-32.
29. Islam MR, Nagao J, Zendo T, Sonomoto K. Antimicrobial mechanism of lantibiotics. Biochem Soc Trans. 2012;40:1528-33. http://dx.doi.org/10.1042/BST20120190

30. Thomas LV, Wimpenny J. Investigation of the effect of combined variations in temperature, $\mathrm{pH}$, and $\mathrm{NaCl}$ concentration on nisin inhibition of Listeria monocytogenes and Staphylococcus aureus. Appl Environ Microbiol. 1996;62:2006-12.

31. Papagianni M, Anastasiadou S. Pediocins: The bacteriocins of Pediococci. Sources, production, properties and applications. Microb Cell Fact. 2009;8:1-16. http://dx.doi.org/10.1186/1475-2859-8-3

32. Thimothe J, Nightingale KK, Gall K, Scott VN, Wiedmann M. Tracking of Listeria monocytogenes in smoked fish processing plants. J Food Prot. 2004;67:328-41.

33. Park SH, Lee JH. The correlation of physico-chemical characteristics of kimchi with sourness and overall acceptability. Kor J Food Cookery Sci. 2005;21:103-9.

34. Shin JH, Kim R, Kang MJ, Kim GM. Quality and fermentation characteristics of garlic-added kimchi. Kor J Food Preserv. 2012;19:539-46.

35. Kim J, Bang J, Beuchat LR, Kim H, Ryu JH. Controlled fermentation of kimchi using naturally occurring antimicrobial agents. Food Microbiol. 2012;32:20-31. http://dx.doi.org/10.1016/j.fm.2012.05.007

36. Jung JY, Lee SH, Lee HJ, Seo HY, Park WS, Jeon CO. Effects of Leuconostoc mesenteroides starter cultures on microbial communities and metabolites during kimchi fermentation. Int J Food Microbiol. 2012;153:378-87. http://dx.doi.org/10.1016/j.ijfoodmicro.2011.11.030

37. Kim M, Chun J. Bacterial community structure in kimchi, a Korean fermented vegetable food, as revealed by $16 \mathrm{~S}$ rRNA gene analysis. Int J Food Microbiol. 2005;103:91-6. http://dx.doi.org/10.1016/j.ijfoodmicro.2004.11.030

38. Lee H, Yoon H, Ji Y, Kim H, Park H, Lee J, et al. Functional properties of Lactobacillus strains isolated from kimchi. Int J Food Microbiol. 2011;145:155-61. http://dx.doi.org/10.1016/j.ijfoodmicro.2010.12.003 